\title{
The Electrophilic Substitution of Sydnones: the Reaction with 3-Aryl-4-Phenylsydnones, 3-Arylmethylsydnones and 3-Phenylethylsydnone
}

\author{
Mei-Fang Ding, Kai-Feng Cheng, Ying-Nan Chen, Shaw-Tao Lin* \\ Department of Applied Chemistry, Providence University \\ 200, Section 7, Taiwan Boulevard, Sha-Lu District, Taichung, Taiwan, 43301 \\ *Corresponding Author: sdlin@pu.edu.tw
}

Copyright (C) 2013 Horizon Research Publishing All rights reserved.

\begin{abstract}
The electrophilic substitution of 3-aryl-4phenylsydnones, 3 -arylmethylsydnones and 3-phenylethylsydnone are studied in order to understand extend of dual nature of the sydnone ring. In the reaction, the nitronium cation is more reactive toward to the aryl ring attached at $\mathrm{N}(3)$. The presence of a methyl or methoxyl group on the benzene ring of the arylalkyl group or of methylene between the aryl and the sydnonyl ring causes the phenyl ring to become electrophilic.
\end{abstract}

Keywords Arylsydnones, Diaryldysnone, Dual Properties, Electrophiles, Nitration

\section{Introduction}

Sydnones undergo electrophilic aromatic substitution reactions, with an ease that is equal to that of furan [1]. For the electrophilic substitution of 3-arylsydnones, the aryl substituent usually competes with the sydnone core. The exclusivity of sydnone ring substitution with the vast majority of electrophiles is attributable to the deactivation of the aryl substituent by the electron-withdrawing effect of the sydnone ring nitrogen (the N-3 position has a substantial fractional positive charge) [2]. Competitive aryl ring substitution has been observed both in the bromination of amino- arylsydnones [3] and in the nitration of some slightly activated arylsydnones [4] that are unsubstituted at the 4-position. The latter results are of considerable interest since they represent the only general examples of aryl ring substitution in competition with the sydnone ring. Recently, results have shown that the nitration of di- and tri-methylphenyl sydnones take place exclusively on the aryl with considerable regioselectively [5]. It is surprising that the parameters that affect concomitant or exclusive substitution on the aryl ring have not been well studied. In order to understand these aspects, we decide to decouple the sydnone core and aryl substituent by placing a methylene spacer between them. From the products distribution, it is possible to understand the effect of the methylene group and the substituent on phenyl ring in the competition between the two rings for the electrophiles.

\section{Results and Discussion}

\subsection{Preparation of Sydnones}

In order to determine how the parameters affect the behavior of the sydnone ring toward to the electrophile, a series of arylalkyl groups at $\mathrm{N}(3)$ substituted sydnones were prepared. A typical preparation procedure, as shown in Scheme 1, was used to prepare 3-arylsydnone, 3-arylmethylsydnones and 3-phenyl- ethylsydnone [6]. The sydnones with a phenyl group at C(4) were prepared by direct coupling of the sydnone and iodobenzene in the presence of $\underline{\mathrm{Pd}(\mathrm{OAc})_{2}}$ and $\underline{\mathrm{PPh}}_{\underline{3}}$ in DMF solution [7] as shown in Scheme 2. 


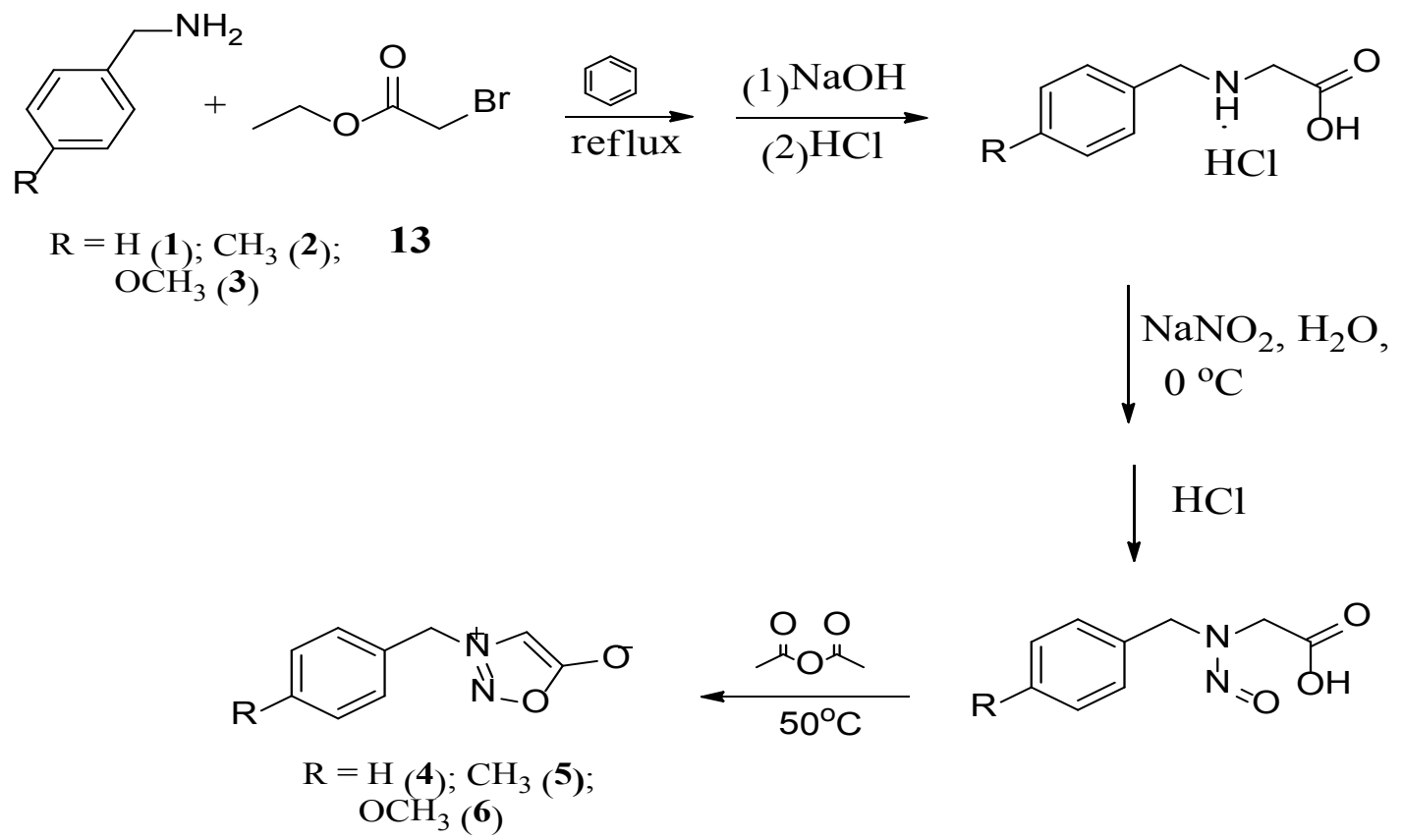

Scheme 1. General pathways used for the preparation of 3-substituted sydnones.<smiles>[R]c1ccc(-[n+]2cc(O)on2)cc1</smiles>

$\underset{\mathrm{Pd}_{(} \mathrm{OAc}_{2}(5 \mathrm{~mol} \%)}{\mathrm{Ph}_{3} \mathrm{P}(10 \mathrm{~mol} \%)}$
$\underset{\text { Iodobenzene }}{\longrightarrow}$

$\mathrm{K}_{2} \mathrm{CO}_{3}$ (2 equiv.)

wet DMF

$120^{\circ} \mathrm{C}$, air

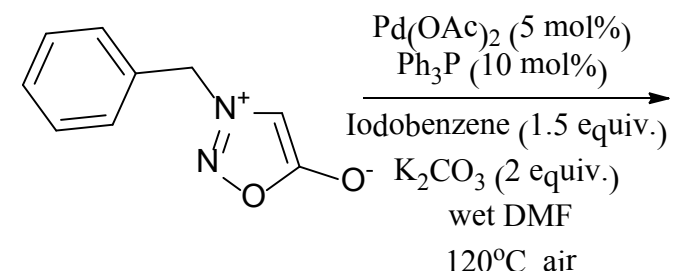

$120^{\circ} \mathrm{C}$, air

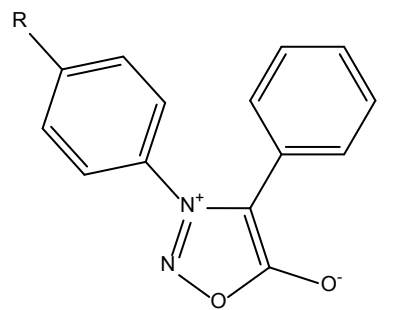

$\mathrm{R}=\mathrm{H}(\mathbf{8}) ; \mathrm{CH}_{3}(\mathbf{9})$;<smiles>[O-]c1on[n+](Cc2ccccc2)c1-c1ccccc1</smiles>

11

Scheme 2. General pathway used for the coupling of the phenyl ring and 3-substituted sydnones.

\subsection{Bromination}

The electrophilic substitution of 3-aryl-alkylsydnone (4-7) is shows in Scheme 3. The bromination of 3-phenylsydnone has been studied extensively [8]. A bromine atom is introduced to the $\mathrm{C}(4)$ position regardless of the bromination methods and the amount of reagents used [9]. This is because the aryl ring is deactivated by the sydnone ring through $\mathrm{N}(3)$. In order to activate the phenyl group towards bromination, we introduced methylene group(s) between the aryl substituent and N(3), as well as an electron-donating group on the aryl ring. It is found that with one equivalent of $\underline{\mathrm{Br}^{+}}$, bromination occurs at the $\mathrm{C}(4)$ position exclusively (entries 1-7, Table 1). Depending on the nature of the reagents used, the bromination can proceeds via either an electrophilic or a radical reaction. However, both processes give the same product, regardless of the reagents used. Once an excess equivalent amount of $\mathrm{Br}_{2}$ is used, the second bromine can be introduced to the phenyl ring of the 4-MeO derivative 6 to yield a dibromo product $15(38 \%)$ and a 4-bromo product 14 (entry 8 , Table 1). The combination of a methylene unit and the methoxy group are activated the phenyl ring toward the electrophile to form 15. However, the introduction of a second bromine into the meta position with respect to $\mathrm{N}(3)$ suggests that the electron-withdrawing character of the sydnone ring directs the substitution position through a methylene unit. 


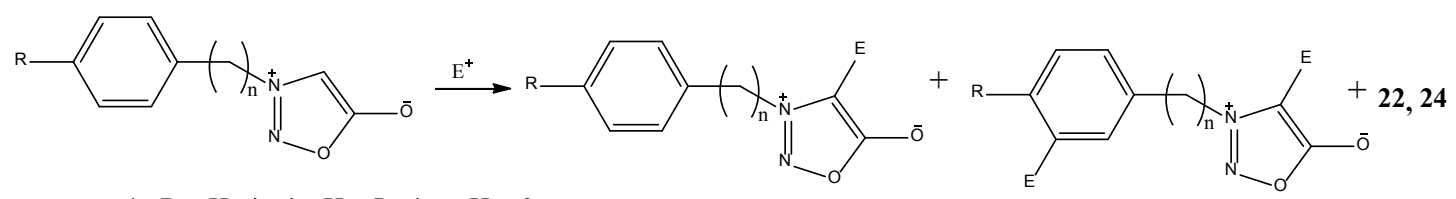

$$
\begin{array}{ll}
\mathrm{n}=1 & \mathrm{R}=\mathrm{H}(\mathbf{4}), 4-\mathrm{CH}_{3}(\mathbf{5}) ; 4-\mathrm{OCH}_{3}(\mathbf{6}) \\
2 & \mathrm{R}=\mathrm{H}(\mathbf{7}) \\
\mathrm{E}^{+}=\mathrm{Br}+(\mathbf{B}) ; \mathrm{CHO}^{+}(\mathbf{F}) ; \mathrm{NO}_{2}{ }^{+}(\mathbf{N}) & \mathbf{1 2 - 1 4} ; \mathbf{1 5 - 1 8 , 2 3}
\end{array}
$$

$15,19,20,21$

Scheme 3. The product distribution obtained from the electrophilic substitution of 3-arylmethyl- and 3-phenylethylsydnones.

\begin{tabular}{|c|c|c|c|c|c|}
\hline Entries & Compd & $\mathrm{n}$ & $\mathrm{R}$ & Reagents $^{\mathrm{a}}$ & Products \\
\hline 1 & 4 & 1 & $\mathrm{H}$ & $\mathrm{Br}_{2} / \mathrm{NaOAc}$ & $12(87 \%)[9]$ \\
\hline 2 & 4 & 1 & $\mathrm{H}$ & $\mathrm{Br}_{2} / \mathrm{Fe}$ & $12(80 \%)[9]$ \\
\hline 3 & 4 & 1 & $\mathrm{H}$ & $\mathrm{NBS} / \mathrm{NaOAc}$ & $12(70 \%)[9]$ \\
\hline 4 & 4 & 1 & $\mathrm{H}$ & $\begin{array}{l}\text { NBS/AIBN, } \\
\text { NaOAc, } h v\end{array}$ & $12(65 \%)[9]$ \\
\hline 5 & 4 & 1 & $\mathrm{H}$ & NBS/peroxide & $12(68 \%)[9]$ \\
\hline 6 & 5 & 1 & 4-Me & $\mathrm{Br}_{2} / \mathrm{NaOAc}$ & $\mathbf{1 3}(81 \%)$ \\
\hline 7 & 6 & 1 & $4-\mathrm{OMe}$ & $\mathrm{Br}_{2} / \mathrm{NaOAc}$ & $\mathbf{1 4}(80 \%)$ \\
\hline 8 & 6 & 2 & 4-OMe & $\mathrm{Br}_{2} / \mathrm{NaOAc}^{\mathrm{b}}$ & $14(48 \%), 15(38 \%)$ \\
\hline 9 & 7 & 1 & $\mathrm{H}$ & $\mathrm{Br}_{2} / \mathrm{NaOAc}$ & $16(69 \%)$ \\
\hline 10 & 4 & 1 & $\mathrm{H}$ & $\mathrm{POCl}_{3} / \mathrm{DMF}^{\mathrm{c}}$ & $17(50 \%)[10]$ \\
\hline 11 & 5 & 1 & 4-Me & $\mathrm{POCl}_{3} / \mathrm{DMF}^{\mathrm{c}}$ & $18(48 \%)$ \\
\hline 12 & 6 & 1 & $4-\mathrm{OMe}$ & $\mathrm{POCl}_{3} / \mathrm{DMF}^{\mathrm{c}}$ & $\begin{array}{ll}----- \\
-1\end{array}$ \\
\hline 13 & 4 & 1 & $\mathrm{H}$ & $\mathrm{KNO}_{3} / \mathrm{H}_{2} \mathrm{SO}_{4}$ & $19(52 \%), 20(7 \%)[12]$ \\
\hline 14 & 5 & 1 & 4-Me & $\mathrm{KNO}_{3} / \mathrm{H}_{2} \mathrm{SO}_{4}$ & $21(69 \%)$ \\
\hline 15 & 6 & 1 & $4-\mathrm{OMe}$ & $\mathrm{KNO}_{3} / \mathrm{H}_{2} \mathrm{SO}_{4}$ & $22(38 \%)^{\mathrm{d}}$ \\
\hline 16 & 7 & 2 & $\mathrm{H}$ & $\mathrm{KNO}_{3} / \mathrm{H}_{2} \mathrm{SO}_{4}$ & $23(46 \%), 24(9 \%)^{\mathrm{e}}$ \\
\hline
\end{tabular}

Table 1. Product distribution from the electrophilic substitution of 3-arylmethyl- and 3-phenylethylsydnones

a,one equivalent of electrophile was used; b. four equivalent of $\mathrm{Br}_{2}$ were used; c. ten equivalent of $\underline{\mathrm{POCl}_{3}}$ and DMF were used; d. 3-(3,5-dinitro-4-methoxyphenyl)sydnone; e. 3-(2-nitrophenylethyl)sydnone.

\subsection{Formylation}

The treatment of 3-phenylsydnone with various acylation reagent, i.e. anhydride or acyl chloride, yield only the $\mathrm{C}(4)$-acetyl derivative. None of the acetyl group is found at the phenyl ring [10]. The Vilsmeier procedure was used to formylate 3-phenylsydnone and also only produced the $\mathrm{C}(4)$-formyl derivative [11]. In the work, the Vilsmeier procedure was used to acylate $\mathbf{4}$ and $\mathbf{5}$ in order to determine the whether a methylene unit reduces the electron-withdrawing ability of sydnone ring through N(3). The isolated products are confirmed as the 4-acyl derivatives $\mathbf{1 7}$ and $\mathbf{1 8}$ (entries 10, 11, Table 1). However, using these reaction conditions, compound $\mathbf{6}$ is decomposed into an unidentified material.

\subsection{The Nitration of 3-arylalkylsydnones}

Of the possible electrophilic substitution of 3 -phenylsydnones, nitration was studied more extensively [4a, 12]. Weintraub and Bambury nitrated 3-phenylsydnone to give only the 4-nitro derivative, with no nitration on the phenyl ring even with an excess of nitronium ions [4a]. Turnbull et.al used methyl group(s) as an electron-donor, in order to activate the phenyl toward the nitronium ion. When the phenyl ring contains two or three methyl group, with a limited amount of nitronium, the nitration only take place at the phenyl ring is regioselective at the meta position, with respect to N(3) [5]. This suggests that the methyl groups can activate the phenyl for the nitration, but the substitution position is still directed by the sydnonyl ring. This study examines the ability of methylene group(s) to isolate the electron-withdrawing ability and the ability to donate of methyl and methoxy group to activate the aryl ring. During the nitration of 3-benzylsydnone 4, 3-(3-nitrophenyl) sydnone 19 was obtained as a major product and 3-(3-nitrophenyl)-4- nitrosydnone $\mathbf{2 0}$ as a minor product (entry 13, Table 1). This products distribution suggests that the methylene group is able to isolate the electron-withdrawing nature of the sydnone ring. In the presence of an additional methyl or methoxyl group the aryl ring is activated even further for the nitration. In the case of $\mathbf{6}$, in the presence of methoxy group, only double nitration at the aryl ring is observed (entry 15, Table 1). For compound 7, which contains a $-\mathrm{CH}_{2} \mathrm{CH}_{2}$ - group, the nitration only takes place at $\mathrm{C} 2$ or $\mathrm{C} 4$ of the phenyl (entry 16, Table 1). This indicates that the $-\mathrm{CH}_{2} \mathrm{CH}_{2}$ - can block the influence of the sydnonyl ring and activates the phenyl ring for electrophilic substitution. 


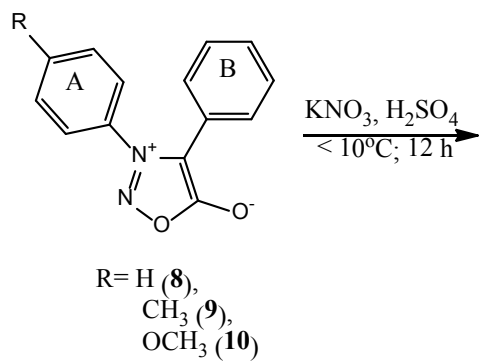

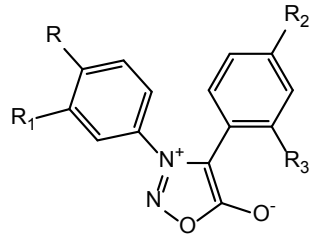

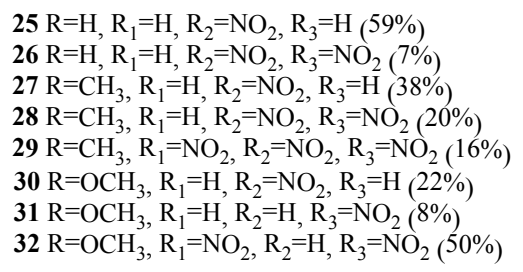

Scheme 4. The Product distribution from the nitration of 3-aryl-4-phenylsydnones using 1.0 eq. amount of $\mathrm{KNO}_{3}$.

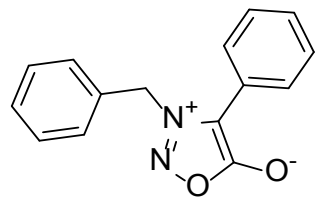

11<smiles>O=[N+]([O-])c1ccc(C[n+]2noc([O-])c2-c2cccc([N+](=O)[O-])c2-c2cccc([N+](=O)[O-])c2)cc1</smiles>

$$
33 \text { yield }=74 \%, 52 \%,--
$$

34 yield $=14 \%, 39 \%, 90 \%$

$$
\begin{gathered}
\underset{1 \mathrm{e}_{\mathrm{q}} \mathrm{KNO}_{3}}{\stackrel{\mathrm{H}_{2} \mathrm{SO}_{4}}{>10^{\circ} \mathrm{C} ; 12 \mathrm{~h}}}
\end{gathered}
$$

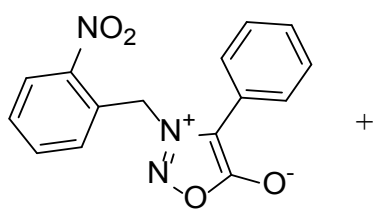

$$
35 \text { yield }=5 \%, 3 \%,--
$$

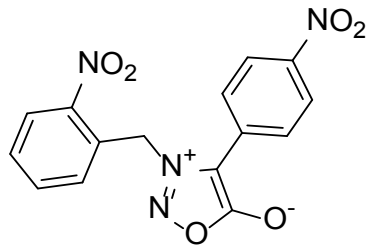

36 yield $=2 \%, 6 \%, 10 \%$

Scheme 5. The product distribution obtained from the nitration of 3-benzyl-4-phenylsydnone $\mathbf{1 1}$ using 1.0, 1.5 and 2.0 eq. amount of $\mathrm{KNO}_{3}$, respectively.

\subsection{The nitration of 3,4-disubstituted sydnones}

Tien isolated 4-(4-nitrophenyl)-3-phenylsydnone as an only product from the nitration of 3,4-diphenylsydnone to demonstrate the dual properties of the sydnonyl ring, i.e. that $\mathbf{N}(3)$ has an electron-withdrawing ability, which deactivates the $\mathbf{N}(3)$-phenyl ring (A), while, $\mathbf{C}(4)$ is an electron-donor that activates the phenyl ring(B) [12]. This study re-examine the same nitration reaction and isolates a minor product that contains two nitro groups on the same ring B (Scheme 4). This indicates the highly electron-donating nature of $\mathbf{C}(4)$. This study introduces either a methyl or a methoxyl group on the N(3)-phenyl ring in order to determine how an electron-donor compensates for this electron-withdrawing ability. For compound $\mathbf{9}$, which contains a methyl group, the nitro groups are mainly introduced to ring B. For compound 10, which contains a methoxy group, the major product yielded contains a nitro group on ring A. The presence of a methoxy group in ring A overcomes the electron-withdrawing ability and activates that phenyl ring toward the electrophile.

In order to further investigate the nitration reaction, a methylene group is introduced between ring $\mathrm{A}$ and N(3). An analysis of the product distribution from the crude nitration products, by comparing the area of methyl groups in the NMR spectra, was used to trace the possible nitration sequence, as shown in scheme 5 . The yields represent the product distribution from 1.0, 1.5 and 2.5 eq. of nitrate ion used. Surprisingly, the first nitro group is introduced into the meta position of ring B, followed by the ortho-position of ring A. 3-(2-Nitrophenyl)-4-(3-nitrophenyl)sydnone $\mathbf{3 4}$ is obtained as a major product and 3-(2-nitrophenyl)-4-(4nitrophenyl)sydnone $\mathbf{3 6}$ as a minor product, when two equivalent amount of nitrate ion are used. From the product distribution from different equivalent amounts of nitrate ion used, it can be concluded that compounds $\mathbf{3 3}$ and $\mathbf{3 5}$ are formed in the early stage and are then converted to $\mathbf{3 4}$ and $\mathbf{3 6}$, respectively.

\section{Conclusion}

Bromonium and formylium ions are less active toward the phenyl ring of 3-arylalkylsydnones and their substitution takes place mainly at the $\mathrm{C}(4)$ position regardless of the presence of methylene unit(s) between the two rings or the amount of electrophile used. The presence of Bronsted acid in the nitration, the protonation of the negatively charged 
oxygen on the sydnone core deactivates it toward elelctrophilic substitution, hence the change in product distribution. For 3,4-diaryl sydnones and 3-benzyl-4-phenylsydnone, nitration take place preferentially at the $\mathrm{C}(4)$-phenyl ring, because of the electron-donating nature of the sydnonyl ring through $\mathrm{C}(4)$.

\section{Experimental}

\subsection{General}

The ${ }^{1} \mathrm{H}$ and ${ }^{13} \mathrm{C}$ NMR spectra were recorded at 400 and $100 \mathrm{MHz}$, respectively, at ambient temperature, using a Bruker Avance-400 spectrometer. The chemical shifts for samples in $\mathrm{CDCl}_{3}$ solution are reported in $\delta$ units relative to TMS. The mass spectra were obtained using GC/MS (Thermo Focus GC coupled with Polaris Q) at an ionization potential of $70 \mathrm{eV}$. All of the samples were introduced into the ionization chamber using a direct insertion probe. Elemental analysis was performed at the Instrumental Analytical Center at National Chung Hsien University. All of the arylalkylsydnones were prepared according to the methods detailed in the literatures and were confirmed by comparing the mp and ${ }^{1} \mathrm{H}$ NMR spectra: 3-phenylsydnone (1) [13]; 3-(4-methylphenyl)sydnone (2) [6]; 3-(4-methoxy phenyl)sydnone (3) [6]; 3-benzylsydnone (4) [14]; 3-(4-methylbenzyl)sydnone (5) [14]; 3-(4-methoxybenzyl)sydnone (6)[14]; phenylethylsydnone (7) [15]; 3,4-diphenylsydnone (8) [16]; 3-(4-methylphenyl)-4phenylsydnone (9) [14]; 3-benzyl-4-phenylsydnone (11) [17].

\subsection{Coupling of the Sydnone Ring and Phenyl Ring:}

The Typical Procedure for preparation of 3,4-diphenylsydnone 8: A mixture of 3-phenylsydnone 1 (47 mg, $0.29 \mathrm{mmol}), \mathrm{Pd}(\mathrm{OAc})_{2}(3 \mathrm{mg}, 0.0145 \mathrm{mmo}), \mathrm{K}_{2} \mathrm{CO}_{3}$ ( $80 \mathrm{mg}, 0.58 \mathrm{mmol}), \mathrm{Ph}_{3} \mathrm{P}(8 \mathrm{mg}, 0.029 \mathrm{mmol})$ and $\mathrm{PhI}(49 \mu \mathrm{L}$, $0.435 \mathrm{mmol})$ in DMF $(1.0 \mathrm{~mL})$ was refluxed for $12 \mathrm{~h}$. After the mixture was cooled to $\mathrm{rt}$, water $(10 \mathrm{~mL})$ was added, followed by extraction (EtOAc, $3 \times 10 \mathrm{~mL}$ ), drying $\left(\mathrm{MgSO}_{4}\right)$, filtering and rotor evaporation to produce a light orange solid. The crude product was subjuect to column chromatographic purification using hexane/EA $(9: 1)$ as an eluent to give 56 $\mathrm{mg}\left(81 \%\right.$ yield) of product $\mathbf{8} . \mathrm{mp}=183-186^{\circ} \mathrm{C}$ (Lit. $\left.183-186^{\circ} \mathrm{C}\right)[15] ;{ }^{1} \mathrm{H}$ NMR $\delta$ 7.26-7.28 (m, 5H), 7.47-7.50 (m, $2 \mathrm{H})$, 7.56-7.60 (m, 2H), 7.68-7.66 (m, $1 \mathrm{H})$ 。

\subsubsection{3-(4-Methylphenyl)-4-phenylsydnone 9:}

yield $68 \%$, mp $151-153^{\circ} \mathrm{C}\left(151 \sim 153^{\circ} \mathrm{C}\right)[15] ;{ }^{1} \mathrm{H}$ NMR $\delta$ $2.47(\mathrm{~s}, 3 \mathrm{H}), 7.26-7.30(\mathrm{~m}, 5 \mathrm{H}), 7.35(\mathrm{~s}, 4 \mathrm{H})$.

\subsubsection{3-(4-Methoxyphenyl)-4-phenylsydnone 10:}

yield $70 \%, \mathrm{mp} 120 \sim 121{ }^{\circ} \mathrm{C} ;{ }^{1} \mathrm{H}$ NMR $\delta 3.89(\mathrm{~s}, 3 \mathrm{H})$, 7.01-7.03 (m, 2H), 7.27-7.31 (m, 5H), 7.38-7.4 (m, $2 \mathrm{H}) ;{ }^{13} \mathrm{C}$
NMR $\delta 55.8,109.2,112.9,121.2,123.5,125.8,127.1$, 128.3, 128.4, 133.6, 153.1, 167.0; MS ( $\mathrm{m} / \mathrm{z}, \%) 268\left(\mathrm{M}^{+}{ }^{\circ}\right.$, $42 \%), 210(100 \%), 167$ (8\%). Anal. calcd for $\mathrm{C}_{15} \mathrm{H}_{12} \mathrm{~N}_{2} \mathrm{O}_{3}$ : C, 67.16; H, 4.51; N, 10.44. Found: C, 67.20; H, 4.55; N, 10.40 .

4.3.3. 3-Benzyl-4-phenylsydnone 11: yield 71\%, yellow solid, mp 97-98 ${ }^{\circ} \mathrm{C}$ (Lit. $98 \sim 100^{\circ} \mathrm{C}$ ) [17]; ${ }^{1} \mathrm{H}$ NMR $\delta$ $7.33 \sim 7.45(\mathrm{~m}, 8 \mathrm{H}), 7.16 \sim 7.18(\mathrm{~m}, 2 \mathrm{H}), 5.52(\mathrm{~s}, 2 \mathrm{H}) ;{ }^{13} \mathrm{C}$ NMR $\delta 167.5,131.3,129.4,129.3,129.1,128.5,127.5$, $124.2,107.8,55.4$.

\subsection{The Bromination of 3-Benzylsydnones:}

A $10 \%$ ethanolic bromine solution $(2.0 \mathrm{~mL}, 1.1 \mathrm{mmol})$ was slowly added to a mixture of 3-benzylsydnone $4(0.19 \mathrm{~g}$, $1.0 \mathrm{mmol})$ in $\mathrm{EtOH}(6.0 \mathrm{~mL})$ and $4 \%$ aq. $\mathrm{NaHCO}_{3}(3 \mathrm{~mL}, 1.5$ $\mathrm{mmol})$. After addition, the mixture was stirred for an additional $30 \mathrm{~min}$ and was then pour onto ice-water $(40 \mathrm{~mL})$. The resultant was extracted with ethyl acetate $(3 \times 20 \mathrm{~mL})$. The combined organic layer was dried over $\mathrm{MgSO}_{4}$, filtered and rotor evaporated to give 3-benzyl-4-bromosydnone $\mathbf{1 2}$ as a light yellow solid, with an $86.5 \%$ yield, mp $106 \sim 107^{\circ} \mathrm{C}$ (Lit. 103.5- 104.0 $\left.{ }^{\circ} \mathrm{C}\right)[9] ;{ }^{1} \mathrm{H}$ NMR $\delta$ 7.39 7.46 (m, 5H), $5.46(\mathrm{~s}$, $1 \mathrm{H}) ;{ }^{13} \mathrm{C}$ NMR $\delta 165.6,130.0,129.7,129.4,128.6,82.9$, 56.8 .

\subsubsection{Bromination of 3-(4-methylbenzyl)sydnone 5:}

3-(4-Methylbenzyl)-4-bromosydnone 13: yield $81.2 \%$, yellow solid, mp $146 \sim 147^{\circ} \mathrm{C} ;{ }^{1} \mathrm{H}$ NMR $\delta 7.29(\mathrm{~d}, 2 \mathrm{H}, J=8.0$ $\mathrm{Hz}), 7.23$ (d, $2 \mathrm{H}, J=8.0 \mathrm{~Hz}), 5.41(\mathrm{~s}, 2 \mathrm{H}), 2.38(\mathrm{~s}, 3 \mathrm{H}) ;{ }^{13} \mathrm{C}$ NMR $\delta$ 165.7, 140.2, 130.0, 128.6, 126.7, 82.7, 56.7, 21.3; MS ( $\mathrm{m} / \mathrm{z}, \%) 268\left(\mathrm{M}^{+},--\right), 105$ (100), 77 (23); Anal. calcd for $\mathrm{C}_{9} \mathrm{H}_{9} \mathrm{BrN}_{2} \mathrm{O}_{2}$ : C, 44.63; H, 3.37; N, 10.41. Found: $\mathrm{C}, 44.62$; $\mathrm{H}, 3.39 ; \mathrm{N}, 10.42$.

\subsubsection{Bromination of 3-(4-methoxybenzyl)sydnone 9 :}

3-(4-Methoxybenzyl)- 4-bromosydnone 14 : yield 80.4\%, yellow solid, mp $102 \sim 103^{\circ} \mathrm{C} ;{ }^{1} \mathrm{H}$ NMR $\delta 7.35(\mathrm{~d}, 2 \mathrm{H}, J=8.8$ $\mathrm{Hz}), 6.93(\mathrm{~d}, 2 \mathrm{H}, J=8.4 \mathrm{~Hz}), 5.39(\mathrm{~s}, 2 \mathrm{H}), 3.82(\mathrm{~s}, 3 \mathrm{H}) ;{ }^{13} \mathrm{C}$ NMR $\delta 165.7,160.8,130.3,121.6,114.7,82.5,56.5,55.4$; $\operatorname{MS}(\mathrm{m} / z, \%) 284\left(\mathrm{M}^{+},--\right), 121(100), 77$ (16); Anal. calcd for $\mathrm{C}_{10} \mathrm{H}_{9} \mathrm{BrN}_{2} \mathrm{O}_{3}: \mathrm{C}, 42.13 ; \mathrm{H}, 3.18 ; \mathrm{N}, 9.83$. Found: $\mathrm{C}, 42.15 ; \mathrm{H}$, $3.17 ; \mathrm{N}, 9.75$.

\subsubsection{Bromination with an Excess of Bromine:}

The same procedure was used, except four-fold bromine was used. After chromatographically separation, 3-(4methoxybenzyl)-4-bromosydnone $14 \quad(48 \%)$ and 3-(3-bromo-4-methoxybenzyl)-4-bromosydnone 15 (38\%) were yielded. Compound $\mathbf{1 5}$ as a yellow solid, $\mathrm{mp}$ $123 \sim 124^{\circ} \mathrm{C} ;{ }^{1} \mathrm{H}$ NMR $\delta 7.62(\mathrm{~s}, 1 \mathrm{H}), 7.34(\mathrm{~d}, 1 \mathrm{H}, J=8.0 \mathrm{~Hz})$, $6.92(\mathrm{~d}, 1 \mathrm{H}, J=8.4 \mathrm{~Hz}), 5.37(\mathrm{~s}, 2 \mathrm{H}), 3.92(\mathrm{~s}, 3 \mathrm{H}),{ }^{13} \mathrm{C} \mathrm{NMR}$ $\delta 165.5,157.3,133.8,129.3,122.9,112.5,112.2,82.6,56.4$, 55.7; MS (m/z, \%) $364\left(\mathrm{M}^{+},--\right), 201$ (99), 199 (100), 77 (35); Anal. calcd for $\mathrm{C}_{10} \mathrm{H}_{8} \mathrm{Br}_{2} \mathrm{~N}_{2} \mathrm{O}_{3}: \mathrm{C}, 33.00 ; \mathrm{H}, 2.22 ; \mathrm{N}, 7.70$. Found: C, 33.06; $\mathrm{H}, 2.24 ; \mathrm{N}, 7.68$. 


\subsubsection{Bromination of 3-Phenylethylsydnone 7:}

3-Phenylethyl-4-bromosydnone 16 : yield $68.8 \%$, yellow solid, mp $110 \sim 111^{\circ} \mathrm{C} ;{ }^{1} \mathrm{H}$ NMR $\delta$ 7.29 7.37 (m, 3H), 7.18 (d, $2 \mathrm{H}, J=8.0 \mathrm{~Hz}), 4.53(\mathrm{t}, 2 \mathrm{H}, J=7.6 \mathrm{~Hz}), 3.29(\mathrm{t}, 2 \mathrm{H}, J=7.6$ $\mathrm{Hz}) ;{ }^{13} \mathrm{C}$ NMR $\delta 165.3,134.5,129.2,128.6,127.9,82.5,54.2$, 34.3; MS (m/z, \%) $270(10.0), 268\left(\mathrm{M}^{+}, 10\right), 105(100)$, 77(29); Anal. calcd for $\mathrm{C}_{10} \mathrm{H}_{9} \mathrm{BrN}_{2} \mathrm{O}_{2}$ : C, 44.63; H, 3.37; N, 10.41. Found: C, 44.62; H, 3.39; N, 10.42 .

\subsection{The Acylation of 3-Benzylsydnone 4:}

Under a nitrogen atmosphere, a mixture of phosphoryl chloride $(1.8 \mathrm{~g}, 12 \mathrm{mmol})$ and DMF $(1.9 \mathrm{~g}, 26 \mathrm{mmol})$ was maintained at a temperature of less than $5^{\circ} \mathrm{C}$ and was stirred for $1 \mathrm{~h}, 3$-benzylsydnone $(0.5 \mathrm{~g}, 2 \mathrm{mmol})$ was added to the mixture at that temperature. After stirring for $30 \mathrm{~min}$, the mixture was allowed to warm to $\mathrm{rt}$ and was stirred for another $12 \mathrm{~h}$. To workup, the mixture was cooled in an ice-bath, followed by the adding of aq. NaOAc $(10 \%, 10$ $\mathrm{mL}$ ), extraction (EtOAc, $3 \times 10 \mathrm{~mL}$ ), drying $\left(\mathrm{MgSO}_{4}\right)$, filtering and rotor evaporation to give 3-Benzyl-4-acylsydnone $\mathbf{1 7}$ as a yellow solid, with a yield of $50.3 \%, \mathrm{mp} 78^{\circ} \mathrm{C}$ (Lit. 79 80 ${ }^{\circ} \mathrm{C}$ ) [10]; ${ }^{1} \mathrm{H}$ NMR $\delta 9.48(\mathrm{~s}, 1 \mathrm{H})$, 7.56 7.48 (m, 5H), 5.87 (s, 2H).

\subsubsection{Acylation of 3-methylphenylsydnone 8:}

3-Methylphenyl-4-acylsydnone 18: yield 48.2\%, yellow solid, mp $105 \sim 106{ }^{\circ} \mathrm{C} ;{ }^{1} \mathrm{H}$ NMR $\delta 9.50(\mathrm{~s}, 1 \mathrm{H}), 7.37(\mathrm{~d}, 2 \mathrm{H}, J$ $=8.0 \mathrm{~Hz}), 7.21(\mathrm{~d}, 2 \mathrm{H} ; J=7.6 \mathrm{~Hz}), 5.83(\mathrm{~s}, 2 \mathrm{H}), 2.36(\mathrm{~s}, 3 \mathrm{H})$; ${ }^{13} \mathrm{C}$ NMR $\delta$ 176.0, 167.7, 140.4, 129.9, 129.1, 127.3, 103.7, 57.5, 21.3; MS (m/z, \%) $204\left(\mathrm{M}^{+}, 2\right), 145$ (43), 90 (100) ; Anal. calcd for $\mathrm{C}_{10} \mathrm{H}_{8} \mathrm{~N}_{2} \mathrm{O}_{3}: C, 58.82 ; \mathrm{H}, 3.95 ; \mathrm{N}, 13.72$. Found: C, 58.84; H, 3.92; N, 13.66 .

\subsection{Typical Processfrthe Nitration Of Sydnones:}

Nitration of 3-benzylsydnone 4. Solid $\mathrm{KNO}_{3}(0.30 \mathrm{~g}, 3$ $\mathrm{mmol})$ was added to a mixture of 3-benzylsydnone $(0.53 \mathrm{~g}$, $3 \mathrm{mmol})$ in $\mathrm{H}_{2} \mathrm{SO}_{4}(10 \mathrm{~mL})$ solution at temperature of less than $10^{\circ} \mathrm{C}$. After stirring for $12 \mathrm{~h}$, the mixture was poured onto an ice-water $(50 \mathrm{~mL})$. The resultant was extracted using ethyl acetate $(3 \times 50 \mathrm{~mL})$. The combined organic layer was dried $\left(\mathrm{MgSO}_{4}\right)$, filtered and rotor evaporated to dryness. The resultant was subjected to column chromatographic separation using a mixture of EA and hexane (1:5 = vol: vol) to give 3-(3-nitrobenzyl)sydnone (19) and 3-(3-nitrobenzyl)-4-nitrosydnone (20). Compound 19: yield $52.6 \%$, yellow solid, mp $110-111^{\circ} \mathrm{C}$ (Lit. $111-112^{\circ} \mathrm{C}$ ) [12]; ${ }^{1} \mathrm{H}$ NMR $\delta 8.34$ (d, $\left.1 \mathrm{H}, J=7.6 \mathrm{~Hz}\right), 8.29(\mathrm{~s}, 1 \mathrm{H}), 7.73$ (d, $1 \mathrm{H}, J=7.6 \mathrm{~Hz}), 7.69(\mathrm{t}, 1 \mathrm{H}, J=7.6 \mathrm{~Hz}), 6.31(\mathrm{~s}, 1 \mathrm{H}), 5.49$ (s, $2 \mathrm{H}$ ). Compound 20: yield $7 \%$, yellow solid, $\mathrm{mp} 136^{\circ} \mathrm{C}$ (lit. $\left.136 \sim 137^{\circ} \mathrm{C}\right)[12] ;{ }^{1} \mathrm{H}$ NMR $\delta 8.26(\mathrm{~s}, 1 \mathrm{H}), 8.15(\mathrm{~d}, 1 \mathrm{H}, J=$ $8.8 \mathrm{~Hz}), 7.71(\mathrm{~d}, 1 \mathrm{H}, J=6.8 \mathrm{~Hz}), 7.54(\mathrm{t}, 1 \mathrm{H}, J=8.0 \mathrm{~Hz})$, $4.84(\mathrm{~s}, 2 \mathrm{H})$.

4.5.1. Nitration of 3-(4-methylbenzyl)sydnone $\mathbf{5}$ :
3-(3-Nitro-4-methylbenzyl)sydnone (21). Yield 69\%, yellow solid, mp $68 \sim 69^{\circ} \mathrm{C} ;{ }^{1} \mathrm{H}$ NMR $\delta 8.03(\mathrm{~s}, 1 \mathrm{H}), 7.52$ (dd, $1 \mathrm{H}, J=8.0,1.6 \mathrm{~Hz}), 7.47(\mathrm{~d}, 1 \mathrm{H}, J=7.6 \mathrm{~Hz}), 6.27(\mathrm{~s}, 1 \mathrm{H})$, $5.41(\mathrm{~s}, 2 \mathrm{H}), 2.65(\mathrm{~s}, 3 \mathrm{H}) ;{ }^{13} \mathrm{C}$ NMR $\delta 168.9,149.5,136.0$, 134.4, 132.6, 129.7, 124.9, 94.7, 55.9, 20.3; MS ( $\mathrm{m} / \mathrm{z}, \%) 235$ $\left(\mathrm{M}^{+},--\right), 150$ (100), 132 (52.0), 120 (23.6); Anal. calcd for $\mathrm{C}_{10} \mathrm{H}_{9} \mathrm{~N}_{3} \mathrm{O}_{4}: \mathrm{C}, 51.07 ; \mathrm{H}, 3.86 ; \mathrm{N}, 17.87$. Found: $\mathrm{C}, 51.08 ; \mathrm{H}$, $3.88 ; \mathrm{N}, 17.87$.

4.5.2.Nitration of 3-(4-methoxybenzyl)sydnone $\mathbf{6}$ : 3-(3,5-Dinitro-4-methoxybenzyl)sydnone (22): yield 38.5\%, yellow solid, $117^{\circ} \mathrm{C} \sim 118^{\circ} \mathrm{C} ;{ }^{1} \mathrm{H}$ NMR $\delta 8.12(\mathrm{~s}, 2 \mathrm{H}), 6.42(\mathrm{~s}$, 1H), $5.47(\mathrm{~s}, 2 \mathrm{H}), 4.11(\mathrm{~s}, 3 \mathrm{H}) ;{ }^{13} \mathrm{C}$ NMR $\delta 168.3,148.4$, 145.7, 129.1, 126.8, 95.1, 65.2, 54.8; MS ( $\mathrm{m} / z, \%) 286\left(\mathrm{M}^{+}\right.$, --), 211 (100), 180 (22.9); Anal. calcd for $\mathrm{C}_{10} \mathrm{H}_{8} \mathrm{~N}_{4} \mathrm{O}_{7}$ : C, 40.55; H, 2.72; N, 18.92. Found: C, 40.55; H, 2.73; N, 18.92.

\subsubsection{Nitration of 3-phenylethyl- Sydnone 7:}

3-(4-Nitrophenylethyl)sydnone (23): yield $46 \%$, yellow solid, mp $76-77^{\circ} \mathrm{C} ;{ }^{1} \mathrm{H}$ NMR $\delta 8.22(\mathrm{~d}, 2 \mathrm{H}, J=8.8 \mathrm{~Hz}), 7.37$ $(\mathrm{d}, 2 \mathrm{H}, J=8.8 \mathrm{~Hz}), 6.23(\mathrm{~s}, 1 \mathrm{H}), 4.56(\mathrm{t}, 2 \mathrm{H}, J=7.2 \mathrm{~Hz}), 3.41$ (t, $2 \mathrm{H}, J=7.2 \mathrm{~Hz}) ;{ }^{13} \mathrm{C}$ NMR $\delta 168.8,147.7,142.2,129.5$, 124.4, 94.8, 53.7, 34.6; MS (m/z, \%) $235\left(\mathrm{M}^{+}, 3\right), 150(100)$, 91 (43.0); Anal. calcd for $\mathrm{C}_{10} \mathrm{H}_{9} \mathrm{~N}_{3} \mathrm{O}_{4}$ : C, 51.07; $\mathrm{H}, 3.86$; N, 17.87. Found: C, 51.08; H, 3.86; N, 17.90. 3-(2-Nitrophenylethyl)sydnone (24): yield 9\%, yellow solid, mp $117-118^{\circ} \mathrm{C} ;{ }^{1} \mathrm{H}$ NMR $\delta 8.12(\mathrm{~d}, 1 \mathrm{H}, J=9.2 \mathrm{~Hz}), 7.60$ (t, $1 \mathrm{H}, J=7.6 \mathrm{~Hz}), 7.53(\mathrm{t}, 1 \mathrm{H}, J=7.2 \mathrm{~Hz}), 6.22(\mathrm{~s}, 1 \mathrm{H}), 4.67(\mathrm{t}$, $2 \mathrm{H}, J=7.6 \mathrm{~Hz}), 3.40(\mathrm{t}, 2 \mathrm{H}, \mathrm{J}=7.2 \mathrm{~Hz}) ;{ }^{13} \mathrm{C}$ NMR $\delta 168.1$, 151.2, 140.7, 134.2, 132.7, 129.5, 125.9, 94.5, 53.4, 33.7; $\operatorname{MS}(\mathrm{m} / z, \%) 235\left(\mathrm{M}^{+}, 11\right), 150(100), 91$ (21.2); Anal. calcd for $\mathrm{C}_{10} \mathrm{H}_{9} \mathrm{~N}_{3} \mathrm{O}_{4}$ : C, 51.07; H, 3.86; N, 17.87. Found: C, 51.09; $\mathrm{H}, 3.84 ; \mathrm{N}, 17.92$.

\subsubsection{Nitration of 3,4-diphenylsydnone 8:}

Same procedure was executed, the resultant was subjected to column chromatogrphic sepatation by using mixture of ethyl acetate and hexane $(1: 8=\mathrm{vol}: \mathrm{vol})$ as an eluent to give 3-phenyl-4-(4-nitrophenyl)sydnone 25 and 3-phenyl-4-(2,4-dinitrophenyl)sydnone 26. Compound 25, yield $59 \%$, yellow solid, $\mathrm{mp} 160-163^{\circ} \mathrm{C}$ (Lit. $\left.162-164^{\circ} \mathrm{C}\right)[16]$; ${ }^{1} \mathrm{H}$ NMR $\delta 7.48(\mathrm{~d}, 2 \mathrm{H}, J=4.8 \mathrm{~Hz}, 2 \mathrm{H}), 7.50-7.52(\mathrm{~d}, 2 \mathrm{H}, J=$ $4.8 \mathrm{~Hz}), 7.67(\mathrm{t}, 2 \mathrm{H}, J=4.8 \mathrm{~Hz}), 7.76(\mathrm{t}, 1 \mathrm{H}, J=8.0 \mathrm{~Hz}), 8.13$ $\left(\mathrm{d}, 2 \mathrm{H}, J=4.8 \mathrm{~Hz}\right.$ ). Compound 26, yield $17 \%$, mp $189-191^{\circ} \mathrm{C}$, yellow solid; ${ }^{1} \mathrm{H}$ NMR $\delta 7.40(\mathrm{~d}, 2 \mathrm{H}, J=6.4 \mathrm{~Hz}$,), $7.56(\mathrm{t}, 2 \mathrm{H}$, $J=6.4 \mathrm{~Hz}$,), $7.66(\mathrm{t}, 1 \mathrm{H}, J=7.6 \mathrm{~Hz}), 7.70(\mathrm{~d}, 1 \mathrm{H}, J=8.8 \mathrm{~Hz}$,), $8.45(\mathrm{dd}, 1 \mathrm{H}, J=8.8,2.4 \mathrm{~Hz}), 8.79(\mathrm{~d}, 1 \mathrm{H}, J=2.4 \mathrm{~Hz},) ;{ }^{13} \mathrm{C}$ NMR $\delta 105.0,118.2,124.8,125.4,128.7,129.6,130.8$, 133.2, 134.1, 147.7, 148.4, 166.1; MS $(m / z, \%) 328\left(\mathrm{M}^{+}, 8\right)$, 270 (100); Anal. calcd for $\mathrm{C}_{14} \mathrm{H}_{8} \mathrm{~N}_{4} \mathrm{O}_{6}: \mathrm{C}, 51.23 ; \mathrm{H}, 2.46 ; \mathrm{N}$, 17.01. Found: C, $51.22 ; \mathrm{H}, 2.48 ; 17.05$.

\subsubsection{The Nitration of 3-(4-methyl- phenyl)-4-phenyl- sydnone 9:}

The same procedure was used except that HPLC separation (RP-18; methanol: water $=45: 55)$ was used to give the products from column in the sequence: 3-(4-methyl3-nitrophenyl)-4-(2,4-dinitrophenyl)sydnone $\quad 27(38 \%)$, 
3-(4-methylphenyl)- 4-(2,4-dinitrophenyl)sydnone 28(20\%) and 3-(methylphenyl)-4-(4-nitrophenyl)sydnone 29(16\%). The yields of the products were estimated according to the ratio of the proton of the methyl group in the NMR spectra of crude product. Compound $27, \mathrm{mp} 149-151^{\circ} \mathrm{C}$, yellow solid; ${ }^{1} \mathrm{H}$ NMR $\delta 2.52(\mathrm{~s}, 3 \mathrm{H}), 7.37(\mathrm{~d}, 2 \mathrm{H}, J=8.8 \mathrm{~Hz}), 7.44(\mathrm{~d}, 2 \mathrm{H}$, $J=8.8 \mathrm{~Hz}), 7.49(\mathrm{~d}, 2 \mathrm{H}, J=8.0 \mathrm{~Hz}), 8.13(\mathrm{~d}, 2 \mathrm{H}, J=8.0 \mathrm{~Hz})$; ${ }^{13} \mathrm{C}$ NMR 39.4, 108.1, 121.4, 123.5, 127.3, 128.3, 129.5, 130.4, 134.3, 148.3, 164.6; MS (m/z, \%) $297\left(\mathrm{M}^{+}, 12\right), 239$ (100); Anal. calcd for $\mathrm{C}_{15} \mathrm{H}_{11} \mathrm{~N}_{3} \mathrm{O}_{4}: \mathrm{C}, 60,61 ; \mathrm{H}, 3.73 ; \mathrm{N}$, 14.14. Found: C, 60.61; H, 3.73; N, 14.17. Compound 28, mp. $163-165^{\circ} \mathrm{C}$; yellow solid, ${ }^{1} \mathrm{H}$ NMR $\delta 2.45$ (s, 3H), 7.25-7.34 (m, 4H), $7.68(\mathrm{~d}, 1 \mathrm{H}, J=8.0 \mathrm{~Hz}), 8.45(\mathrm{dd}, 1 \mathrm{H}, J=$ 8.0, $2.4 \mathrm{~Hz}$ ), $8.85(\mathrm{~d}, 1 \mathrm{H}, J=2.4 \mathrm{~Hz}) ;{ }^{13} \mathrm{C}$ NMR $\delta 21.5$, 108.1, 121.4, 124.3, 126.8, 127.2, 128.6, 129.7, 130.5, 1462, 165.0; MS ( $\mathrm{m} / \mathrm{z}, \%) 342\left(\mathrm{M}^{+}, 8\right), 288$ (100); Anal. calcd for $\mathrm{C}_{15} \mathrm{H}_{10} \mathrm{~N}_{4} \mathrm{O}_{6}: \mathrm{C}, 52.64 ; \mathrm{H}, 2.94 ; \mathrm{N}, 16.37$. Found: $\mathrm{C}, 52.66 ; \mathrm{H}$, 2.92; N, 16.41. Compound 29, mp. $192-193^{\circ} \mathrm{C}$, yellow solid, ${ }^{1} \mathrm{H}$ NMR $\delta 2.72(\mathrm{~s}, 3 \mathrm{H}), 7.58(\mathrm{~s}, 1 \mathrm{H}), 7.58(\mathrm{~d}, 1 \mathrm{H}, J=2.0 \mathrm{~Hz})$, $7.79(\mathrm{~d}, 1 \mathrm{H}, J=8.4 \mathrm{~Hz}), 8.04(\mathrm{~d}, 1 \mathrm{H}, J=2.0 \mathrm{~Hz}), 8.53(\mathrm{dd}$, $1 \mathrm{H}, J=2.4,8.4 \mathrm{~Hz}), 8.85(\mathrm{~d}, 1 \mathrm{H}, J=2.4 \mathrm{~Hz}) ;{ }^{13} \mathrm{C}$ NMR 21.3 , $108.7,118.7,121.5 ; 122.8,123.4,125.9,128.9,130.4,133.5$, 144.6, 148.2, 164.3; MS (m/z, \%) $387\left(\mathrm{M}^{+}, 4\right), 329(100)$; Anal. calcd for $\mathrm{C}_{15} \mathrm{H}_{9} \mathrm{~N}_{5} \mathrm{O}_{8}: \mathrm{C}, 46.52 ; \mathrm{H}, 2.34 ; \mathrm{N}, 18.08$. Found: C, 46.53; H, 2.32; N, 18.11 .

\subsubsection{The nitration of 3-(4-methoxyphenyl)-4-phenyl- sydnone 10:}

The same procedure as that for the nitration of 3-(3-methylphenyl)-4-phenyl sydnone was used, except that the reaction was conducted at $0^{\circ} \mathrm{C}$. After work-up, the resultant was subjected to HPLC separation. The sequence of the products was accordancewith the order of elution of the HPLC column and the conversion rates were estimated according to the area ratios of the proton of the methoxyl group in the crude product.

3-(4-Methoxyphenyl)-4-(4-nitrophenyl)sydnone 30 , yield $22 \%, \mathrm{mp} .141-142^{\circ} \mathrm{C} ;{ }^{1} \mathrm{H}$ NMR $\delta 3.93$ (s, 3H), 7.10 (d, 2H, $J$ $=9.2 \mathrm{~Hz}), 7.42(\mathrm{~d}, 2 \mathrm{H}, J=9.2 \mathrm{~Hz}), 7.51(\mathrm{~d}, 2 \mathrm{H}, J=8.8 \mathrm{~Hz})$, $8.14(\mathrm{~d}, 2 \mathrm{H}, J=8.8 \mathrm{~Hz})$; MS $(m / z, \%) 313\left(\mathrm{M}^{+}, 9\right), 255$ (100); Anal. calcd for $\mathrm{C}_{15} \mathrm{H}_{11} \mathrm{~N}_{3} \mathrm{O}_{4}: \mathrm{C}, 57.51 ; \mathrm{H}, 3.54 ; \mathrm{N}$, 13.43. Found: C, 57.50; H, 3.53; N, 13.42 . 3-(4-Methoxyphenyl)-4-(2-nitrophenyl)sydnone 31, yield $8 \%$, mp. $135-137^{\circ} \mathrm{C} ;{ }^{1} \mathrm{H}$ NMR $\delta 3.84$ (s, 3H), 6.94 (d, 2H, $J$ $=9.2 \mathrm{~Hz}), 7.31(\mathrm{~d}, 2 \mathrm{H}, J=9.2 \mathrm{~Hz}), 7.48(\mathrm{~d}, 1 \mathrm{H}, J=8.8 \mathrm{~Hz})$, $7.55(\mathrm{t}, 1 \mathrm{H}, J=8.8 \mathrm{~Hz}), 7.66(\mathrm{t}, 1 \mathrm{H}, J=8.8 \mathrm{~Hz}) ; 8.02(\mathrm{~d}$, $1 \mathrm{H}, J=8.8 \mathrm{~Hz}) ;{ }^{13} \mathrm{C}$ NMR $\delta 55.2,106.5,114.0,115.8$, $119.0,124.8,127.8,129.3,129.5,136.2,147.6,159.8$, 165.2; MS (m/z, \%) $313\left(\mathrm{M}^{+}, 6\right), 265$ (100); Anal. calcd for $\mathrm{C}_{15} \mathrm{H}_{11} \mathrm{~N}_{3} \mathrm{O}_{5}$ : C, 57.51; H, 3.54; N, 13.43. Found: C, 57.51; $\mathrm{H}, 3.55$; N, 13.45. 3-(4-Methoxy-3-nitrophenyl)-4-(4-nitrophenyl)sydnone 32, yield $45 \%$, mp. $132-134^{\circ} \mathrm{C} ;{ }^{1} \mathrm{H}$ NMR $\delta$ 4.12 (s, 3H), 7.35 (d, $1 \mathrm{H}, \mathrm{J}=9.2 \mathrm{~Hz}$ ), 7.53 (d, 2H, J = 8.8 $\mathrm{Hz}), 7.68(\mathrm{dd}, 1 \mathrm{H}, \mathrm{J}=9.2,2.4 \mathrm{~Hz}), 8.12(\mathrm{~d}, 1 \mathrm{H}, \mathrm{J}=2.4 \mathrm{~Hz})$, $8.20(\mathrm{~d}, 2 \mathrm{H}, \mathrm{J}=9.2 \mathrm{~Hz}) ;{ }^{13} \mathrm{C}$ NMR $\delta 55.4,108.1,115.8$, $116.2,122.9,124.2,127.4,131.5,134.0,141.6,144.5$, 153.2, 165.6; $\mathrm{MS}(\mathrm{m} / \mathrm{z}, \%) 358\left(\mathrm{M}^{+}, 5\right), 300(100)$; Anal. calcd for $\mathrm{C}_{15} \mathrm{H}_{10} \mathrm{~N}_{4} \mathrm{O}_{7}$ : C, 50.29; H, 2.81; N, 15.64. Found: C, $50.31 ; \mathrm{H}, 2.85 ; \mathrm{N}, 15.70$.

\subsubsection{Nitration of 3-benzyl-4-phenylsydnone 11:}

3-Benzyl-4-(3-nitrophenyl)sydnone 33 , yield $73.5 \%$, yellow solid, mp $112-113^{\circ} \mathrm{C} ;{ }^{1} \mathrm{H}$ NMR $\delta 8.24(\mathrm{t}, 1 \mathrm{H}, J=8.0$ $\mathrm{Hz}), 8.02(\mathrm{~s}, 1 \mathrm{H}), 7.58(\mathrm{t}, 1 \mathrm{H}, J=8.0 \mathrm{~Hz}), 7.52(\mathrm{~d}, 1 \mathrm{H}, J=7.6$ $\mathrm{Hz}), 7.44 \sim 7.49(\mathrm{~m}, 3 \mathrm{H}), 7.35 \sim 7.38(\mathrm{~m}, 2 \mathrm{H}), 5.62(\mathrm{~s}, 2 \mathrm{H}) ;{ }^{13} \mathrm{C}$ NMR $\delta 167.2,148.5,133.6,132.9,130.6,130.0,129.5,128.6$, 124.6, 123.7,123.2, 108.1, 54.3; MS (m/z, \%) 297 (31), 136 (100), 105 (33); Anal. calcd. for $\mathrm{C}_{15} \mathrm{H}_{12} \mathrm{~N}_{3} \mathrm{O}_{4}$ : C, 60.40; $\mathrm{H}$, 4.06; N, 14.09. Found: C, 60.44; H, 4.07; N, 14.05. 3-(4-Nitrobenzyl)-4-(3-nitrophenyl)sydnone $\quad 34$, yield $13.9 \%$, yellow solid, mp $70-72{ }^{\circ} \mathrm{C} ;{ }^{1} \mathrm{H}$ NMR $\delta 8.31(\mathrm{~d}, 3 \mathrm{H}, \mathrm{J}=$ $8.8 \mathrm{~Hz}), 8.13(\mathrm{~s}, 1 \mathrm{H}), 7.69(\mathrm{~d}, 2 \mathrm{H}, J=8.8 \mathrm{~Hz}), 7.64(\mathrm{t}, 1 \mathrm{H}, J$ $=8.0 \mathrm{~Hz}), 7.57(\mathrm{~d}, 1 \mathrm{H}, J=8.0 \mathrm{~Hz}), 5.77(\mathrm{~s}, 2 \mathrm{H}) ;{ }^{13} \mathrm{C}$ NMR $\delta$ $166.4,148.7,147.6,133.3,132.2,130.9,130.3,128.0,124.9$, 124.6, 122.8, 105.8, 55.3; MS $(\mathrm{m} / \mathrm{z}, \%) 343(\mathrm{M}+.,--), 136$ (100), 89 (78.1); Anal. calcd for $\mathrm{C}_{15} \mathrm{H}_{11} \mathrm{~N}_{4} \mathrm{O}_{6}: \mathrm{C}, 52.48 ; \mathrm{H}$, 3.23; N, 16.32; Found: C, 52.49; H, 3.27; N, 16.27. 3-(2-Nitrobenzyl)-4-phenylsydnone 35, yield 5.3\%, yellow solid, $\mathrm{mp} 110-111^{\circ} \mathrm{C} ;{ }^{1} \mathrm{H}$ NMR $\delta 8.25(\mathrm{~d}, 1 \mathrm{H}, J=7.6 \mathrm{~Hz})$, $7.73(\mathrm{t}, 1 \mathrm{H}, J=7.2 \mathrm{~Hz}), 7.64(\mathrm{t}, 1 \mathrm{H}, J=7.6 \mathrm{~Hz}), 7.40(\mathrm{~s}, 5 \mathrm{H})$, $7.25(\mathrm{~d}, 1 \mathrm{H}, J=8.4 \mathrm{~Hz}), 6.00(\mathrm{~s}, 2 \mathrm{H}) ;{ }^{13} \mathrm{C}$ NMR $\delta 167.2$, $147.1,134.9,130.6,129.7,129.4,129.3,127.8,127.1,126.0$, 123.8, 108.6, 53.0; MS (m/z, \%) $298\left(\mathrm{M}^{+},--\right), 136(100), 78$ (51.0); Anal. calcd for $\mathrm{C}_{15} \mathrm{H}_{12} \mathrm{~N}_{3} \mathrm{O}_{4}$ : C, 60.40; H, 4.06; N, 14.09. Found: C, 60.44; H, 4.03; N, 14.06 . 3-(2-Nitrobenzyl)-4-(4-nitrophenyl)sydnone 36, yield $2 \%$, yellow solid, mp $102-104^{\circ} \mathrm{C} ;{ }^{1} \mathrm{H}$ NMR $\delta 8.32(\mathrm{~d}, 1 \mathrm{H}, J=8.4$ $\mathrm{Hz}), 8.28(\mathrm{~d}, 2 \mathrm{H}, J=8.8 \mathrm{~Hz}), 7.77$ (t, $1 \mathrm{H}, J=8.0 \mathrm{~Hz}), 7.71$ $(\mathrm{m}, 3 \mathrm{H}), 7.28(\mathrm{~d}, 1 \mathrm{H}, J=8.0 \mathrm{~Hz}), 6.10(\mathrm{~s}, 2 \mathrm{H}) ;{ }^{13} \mathrm{C} \mathrm{NMR} \delta$ 168.7, 147.9, 147.3, 135.1, 131.2, 130.4, 129.8, 127.5, 126.4, 125.9, 124.6, 106.6, 54.2; MS (m/z, \%) $343\left(\mathrm{M}^{+}\right.$, ---), 136 (100), 89 (86.9); Anal. calcd for $\mathrm{C}_{15} \mathrm{H}_{11} \mathrm{~N}_{4} \mathrm{O}_{6}$ : C, 52.48; $\mathrm{H}$, 3.23 ; N, 16.32. Found: C, 52.47; H, 3.26; N, 16.32 .

\section{Acknowledgements}

The financial support provided by the National Science Council of the Republic of China and the technical support of the HSCC are both gratefully acknowledged.

\section{REFERENCES}

[1] M. Ohta, H. Kato. "In nonbenzoid aromatics", Vol. 1, J. P. Snyder, ed. Academic Press, Inc., New York, NY, 1969, p 146; b). J. M. Lopchuk. "Mesoionics" in "Topics Heterocyclic Chemistry", Vol. 29, B. U. W. Maes, R. R. Gupta, A. I. Meyers ed., Springer-Verlag, Berlin Heidelberg, 2012, p. 381-414.

[2] C. Tin-Lok, J. Miller, F. Stansfield. The $\mathrm{S}_{N}$ mechanism in aromatic com- pounds. Part XXX. The sydnone, J. Chem. Soc. 1213, 1964. 
[3] S. J. Hodson, K.Turnbull. Bromination of sydnones. II Bromination of 3-(2-aminophenyl)sydnone and related compounds, J. Heterocyclic Chem. Vol. 22(5), 1223, 1985.

[4] a). P. M. Weintraub, R. E. Bambury, Heterocycles II. Nitration of 3-arylsydnones, Tetrahedron Lett., Vol. 10(7), 579,$1969 ;$ b). H. J. Tien, S. T. Lin, J. T. Sheu. Nitration of 3-aryl-4-acetylsydnones: Preparation of 3-(3-nitroaryl)sydnones by using acetyl group as a blocking group, Can. J. Chem. Vol. 72, 1610, 1994..

[5] K. Turnbull, T. L. Blackburn, J. J. Miller. Nitration of sydnones: Reaction with 3-arylsydnones containing electrondonors on the aryl ring, J. Heterocyclic Chem. Vol. 33(2), 485, 1996.

[6] Y. Ogata, A. Kawasaki, H. Kojoh. Kinetics of the formation of N-arylsydnones from N-nitroso-N-arylglycines, J. Org. Chem. Vol. 39, 3676, 1974.

[7] A. Rodriguez, R. Vennessy, W. J. Moran. Palladium-catalysed direct alkenylation of sydnones. Tetrahedron Lett. Vol. 50(27), 3942, 2009.

[8] a). C. V. Greco, J. R. Mehta. Meso-ionic compounds. XI, photochromic 4-halo- geno-3-(3-pyridyl)sydnones, J. Heterocycl. Chem. Vol. 16(5), 1059, 1979; b). H. J. Tien, M. Y. Yeh, C. Y. Hwang. A study of the sydnone compounds: Bromination and chlorination (III), J. Chin. Chem. Soc. Vol. 32(4), 461, 1985.

[9] V. G.Yashunskii, S.A. Zotova. Sydnones and sydnone imines. XL. Effect of substituents in the 4- position on the stability of the sydnone ring", Zh. Org. Khim., Vol. 4(5), 901, 1968 (RUSS).

[10] a). H. J. Tien, S. T. Lin, G. T. Og. Bromination of 3-Aryl-4-acetylsydnones with Potassium Bromide and
Sulfuric Acid, J. Chin. Chem. Soc. Vol. 41(6), 813, 1994; b). C. V. Greco, J. Tohias, L. B. Kier, Acylation of 3-phenylsydnone with carboxylic acids and phosphorus pentaoxide, J. Heterocyclic Chem. Vol. 4(1), 160, 1967; c). H. J. Tien, J. Y. Cherng, S. T. Lin. Reduction of acetylsydnones with borohydride anion: Preparation of 4-(1-hydroxyethyl)sydnones, J. Chin. Chem. Soc., Vol. 42(6), 987, 1995.

[11] C. J. Thoman, S. J. Denys, D. J. Voaden, I. M. Hunsberger. Direct formylation of sydnones, J. Org. Chem. Vol. 29(7), 2044, 1964.

[12] H. J. Tien, T. Nonaka, T. Fuchigami, T. Sekine, M. Ohta. Nitration of sydnone compounds. The dual properties of sydnone ring, Nippon Kagaku Zasshi, Vol. 99, 1310, 1978.

[13] M. R. Hearne, R. J. W. LeFevre. Molecular polarizability: the molar Kerr constants of five sydnones, J. Chem. Soc. 4753, 1962.

[14] V. G. Claude, H. N. Wayne, C. C. Cheng. Synthesis of sydnone and sydnone imines, J. Med. Pharm. Chem. Vol. 5, $861,1962$.

[15] M. Nakalima, J. P. Anselme. Reaction of sydnones with oxygen, J. Org. Chem. Vol. 48, 1444, 1983.

[16] A. Rodriguez, W. J. Moran. Palladium- catalyzed direct arylation of sydnone, Synthesis, 650, 2009.

[17] C. Csongar, I. Mueller, H. Slezak, H. J. Klebsch, G. Tomaschewski. Synthese einiger neuer, 4-Diaryl-sydnone, J. Prakt. Chemie. (Leipzig), Vol. 330(6), 1006, 1988.

[18] B. K. Lemont, D. Devindra. Synthesis of sydnones as potential therapeutic agents, J. Pharm. Sci. Vol. 51, 1058, 1962. 